\title{
School Entrepreneurship: A Favorable Context for the Interdisciplinary Projects
}

\author{
Maude Boulanger, Ph.D. Candidate (Corresponding author) \\ Department of Human Kinetics, University of Quebec at Trois-Rivières \\ 3351, boul. des Forges, Trois-Rivieres, Quebec, G9A 5H7, Canada \\ Tel.: 1-819-376-5011, ext. 3377, Fax: 1-819-376-5092. \\ E-mail: maude.boulanger@uqtr.ca \\ Marie-Claude Rivard, Ph.D. \\ Department of Human Kinetics, University of Quebec at Trois-Rivières \\ 3351, boul. des Forges, Trois-Rivieres, Quebec, G9A 5H7, Canada \\ Tel.: 1-819-376-5011, ext. 3781, Fax: 1-819-376-5092 \\ E-mail: marie-claude.rivard@uqtr.ca
}

Rollande Deslandes, Ph.D.

EducationDepartment, University of Quebec at Trois-Rivières

3351, boul. des Forges, Trois-Rivieres, Quebec, G9A 5H7, Canada

Tel.: 1-819-376-5011, ext. 3656

E-mail: rollande.deslandes@uqtr.ca

Received: Nov. 13, 2017 Accepted: Jan. 8, 2017 Published: February 1, 2018

doi:10.5296/jse.v8i1.12325 URL: https://doi.org/10.5296/jse.v8i1.12325

\begin{abstract}
Entrepreneurship education appears to be a promising avenue for developing entrepreneurial skills among young people, this tendency being present in several countries. School is a privileged environment and is targeted since young people are key players in promoting economic growth. The appropriate teaching method for achieving academic and
\end{abstract}




\section{Macrothink}

entrepreneurial goals seems to be the project-based approach. In this regard, entrepreneurship is a privileged context for realization of interdisciplinary projects in order to give meaning to the learning experience. The objective of this study is to describe the process of implementation and deployment of interdisciplinary projects in the context of the entrepreneurial school. Eight individual interviews were conducted with school staff from an entrepreneurial school where several interdisciplinary projects were going on. Our results show that the teacher assumes a key role as a guide throughout the interdisciplinary project in making sure that the education program objectives are attained. However, the lack of collaboration among the teachers remains a challenge in order to equip and help them with the realization of the interdisciplinary projects. Solutions can be identified to facilitate and perpetuate the implementation of these projects in this entrepreneurial context.

Keywords: entrepreneurial school, project-based learning, interdisciplinary project, qualitative study; case study 


\section{Introduction}

For some years, a promotion of entrepreneurial culture has been taking place in different countries to stimulate and diversify economic growth (European Commission, 2013; Secrétariat à la jeunesse, 2016). It seems that young people are expecially targeted by this entrepreneurial movement in order to give them tools to develop their entrepreneurial spirit, since they are considered as key actors to achieving economic growth (European Commission, 2013; Secrétariat à la jeunesse, 2016). Based on these observations, several countries of Europe stand out. An action plan entitled Entrepreneurship 2020: Reigniting the entrepreneurial spirit in Europe has been developed by the European Commission. This plan is based on three areas of intervention, one of which is dedicated to the promotion of education and training for entrepreneurship in order to support growth and the creation of businesses (European Commission, 2013). The initial idea behind this intervention is to be able to implement effective entrepreneurship teaching and learning methods in schools to develop entrepreneurial skills (European Commission, 2013). Over the years, several European countries have distinguished themselves and have implemented national strategies to respond to the challenges related to the acquisition of entrepreneurial skills at school, such as Finland, Sweden and Norway (Eurydice Network, 2012). A study carried out by Huber and his colleagues (2014) confirmed the development of entrepreneurial skills, such as motivation, leadership, and team work, through an entrepreneurial project carried out in Netherlands schools.

The Network for Teaching Entrepreneurship's (NFTE) was established in 1987 in USA and is still present in more than 10 countries around the world (Note 1). NFTE is an international non-profit organization and its mission is to develop entrepreneurial skills among young people to excel in an innovation economy. With the help of their programs, this organization wants to develop skills such as self-reliance, critical thinking and collaboration. Entrepreneurs in Action is another American program that values entrepreneurship for young people. The mission of this program is to increase the economic engagment of young people through education, employment and entrepreneurship. Structured learning activities are proposed to encourage young people to be innovative, to experiment and to develop their potential as entrepreneurs, creators and leaders (Note 2). Junior Achievement is another non-profit organization and it was created in the United States in 1919. It is now established in more than 100 countries(Note 3), including Canada. Using its component related to entrepreneurship, Junior Achievement aims to inspire and prepare young people to succeed in a global economy.

Entrepreneurial Adventure is a Canadian initiative implemented in schools and its main goal is to develop the entrepreneurial spirit, financial literacy, innovative thinking and social responsibility among young people (Note 4). More specifically in the province of Quebec, two government initiatives promote the entrepreneurial culture of young people through schools: the Youth Entrepreneurship Challenge and Youth Action Strategy (Secrétariat à la jeunesse, 2004, 2016). 
As a result of this brief review of initiatives and programs, it seems that education is important to promote entrepreurship and schools play a leading role in developing entrepreneurial skills among young people in several countries around the world. Specifically in Quebec, because this study was done in this province, an entrepreneurial school implements various projects whose primary objective is to innovate and carry out actions to produce a service, a product or an event in order to respond to a need arising from the school environment (Ministère de l'Éducation, du Loisir et du Sport [MELS], 2006). In this context, students produce meaningful and concrete output that has a social impact and positive repercussions (MELS, 2006). The project implemented in this specific entrepreneurial context also aims to develop students' disciplinary learning since the teacher who implements this type of project develops not only the entrepreneurial skills in her/his class but also the pedagogical objectives she/he wishes to achieve for the students (MELS, 2006). Through the deployment of these projects, students develop various entrepreneurial skills, including self-confidence, teamwork and motivation (MELS, 2006). Based on these facts, we can therefore argue that project-based learning seems to be the favorable teaching method for promoting and developing entrepreneurship among students. For this purpose, the Ministère de l'Éducation, du Loisir et du Sport (MELS, 2005) (Quebec Ministry of Education, Recreation and Sport) states that school entrepreneurship is precisely a project culture in which students take action to produce something new and change.

\section{Brief literature review}

\subsection{Project-based learning}

Project-based learning is defined by Proulx (2004) as a process of acquiring and transferring knowledge in which the student must anticipate, plan and realize an observable project that results in a real and evaluable product. Perrenoud (1998) addresses project-based learning as a class-led collective enterprise that leads to concrete production. This enterprise includes a set of tasks in which students have to get involved and play active roles. Blumenfeld and his colleagues (1991) add that there are two essential components for realization projects: they must have a starting question or problem which is used to organize and conduct activities and these activities must lead to the realization of a final product. The literature review by Thomas (2000) reiterates these findings and puts into evidence criteria specific to project-based learning including centrality and driving question. Project-based learning is the main teaching strategy used by the teacher and through the project, students learn the knowledge related to the disciplines involved in the project. The criterion related to the driving question emphasizes that it's essential to have a question or a starting problem that leads students to encounter the central concepts and principles of a discipline. Project-based learning prioritizes the "pedocentric" approach in the sense that students can choose, design and realize entire projects (Proulx, 2004). This method of learning is thus centered on the learner (Grant, 2002). In this context, the teacher must supervise the entire project and act as a pedagogical mediator between the student and the learning to be acquired (Arpin \& Capra, 2001; Proulx, 2004). This type of learning also favors the "sociocentric" approach of pedagogy because the student is in constant interaction and communication with peers, teacher and community to implement the project (Proulx, 2004). 
Project-based learning enables students to engage in building their knowledge, developing their skills and learning at their own pace (Arpin \& Capra, 2001; Bell, 2010). The realization of projects fosters autonomy and a sense of responsibility, allows the experimentation of complex and meaningful learning situations and connects new knowledge with previous knowledge (Arpin \& Capra, 2001). Project-based learning provides a better understanding of the topic, more in-depth learning, improved communication skills and motivation to learn (Bell, 2010). Blumenfeld and his colleagues (1991) add that the realization of projects arouses the students' interest because, working with their peers, they must solve authentic problems in order to construct real solutions. These projects also improve deep understanding because students learn and use the information, concepts and principles needed to implement projects (Blumenfeld, Soloway, Marx, Krajcik, Guzdial, \& Palincsar, 1991).

\subsection{Interdisciplinary}

According to the literature, it seems that project-based learning is the pedagogical strategy to prioritize for implement interdisciplinary in schools (Larose \& Lenoir, 1998; LeDoux, 2003). The study by Hasni (2010) adds that the use of the project is the teaching method that better characterizes interdisciplinary education. Mansilla (2005) defines interdisciplinarity as the ability to integrate the knowledge and thinking patterns of two or more school disciplines in order to produce cognitive advancement, such as explaining a phenomenon, solving a problem or the creation of a product, among others. According to Schneider (1997), interdisciplinarity allows the combination of knowledge and methods from several disciplines that together help to understand some phenomena that cannot be understood or solved by a single discipline. Cone and colleagues (1998) add that interdisciplinary learning is an educational process where several school disciplines are integrated in order to promote better learning in each discipline. Lenoir (2013) defines interdisciplinary study as the action of linking two or more disciplines at the curricular, didactic and pedagogical levels, and leads to the establishment of different links of complementarity and cooperation in order to promote integration of learning processes and knowledge among learners.

Interdisciplinarity allows the exploration and exploitation of academic knowledge and promotes reinvestment in current and concrete practices that concern both, young people and society (Hasni, Lenoir, Larose, Samson, Bousadra, \& Dos Santos, 2008; LeDoux, 2003). Interdisciplinary teaching is based on utilitarian purpose, that is translated through the link with the concrete and life outside the school context (Hasni et al., 2008) and pedagogical-affective purposes, such as increasing student motivation and diversification of pedagogical approaches (Hasni et al., 2008; Samson, Hasni, \& Ducharme-Rivard, 2012). During an interdisciplinary project, the student explores in order to find answers to his/her questions. He/she can make connections and transfer with the experience, newly acquired knowledge and the disciplinary contents (LeDoux, 2003).

\section{Relevance and objective}

To our knowledge, there have been few studies that have addressed the qualitative perspectives of school staff (teachers and principals) in order to have a thorough understanding of the process and the steps involved in implementing and deployment of 
interdisciplinary projects in the specific context of school entrepreneurship. Pépin (2011) argues that entrepreneurship is a privileged context in which to support interdisciplinary in order to lead the student to acquire new knowledge and to give meaning to the learning experience. The report of the European Commission, Education, Audiovisual and Culture Executive Agency [EACEA] and Eurydice (2012) reiterates the finding of Pépin (2011) and highlights that the majority of educational activities implemented to develop entrepreneurial skills use interdisciplinary methods. This study has the advantage of using the theoretical framework of Proulx (2004) to examine in depth the implementation and deployment of these interdisciplinary projects through its four predefined steps. Thus, the main objective of this study is to describe the processes of implementation and deployment of interdisciplinary projects in the context of the entrepreneurial school.

\section{Theoretical framework}

The steps for project implementation developed by Proulx (2004), inspired by Ledoux (2003), serve as theoretical and methodological foundations for this study. This theoretical framework consists of 4 steps related to the implementation of pedagogical projects: (1) Preparation, (2) Implementation, (3) Evaluation, and (4) Disposition. These steps aim to clarify the educational intention, to choose the themes of the project and to structure the major stages of it. Subsequently, when the project is implemented, it's necessary to create student teams to be able to collect all the information and resources available. At this stage, an emphasis is placed on project coordination and supervision and on having common thread throughout the project (step 2). During the third step, evaluation processes are also implemented by the types and the evaluation methods being used. The project concludes with the disposition and presentation of the project to the class, to the school and/or to the community (step 4). Depending on the nature of the pedagogical project, the order of steps 3 (evaluation) and 4 (disposition) may be reversed. For example, the disposition of project can be an integral part of its evaluation and in this case, the third and fourth steps are integrated (Proulx, 2004). In summary, the description of the process surrounding the implementation of the projects will be treated through the first step of the preparation of Proulx (2004). The description of the process surrounding the deployment of the projects will be discussed with steps two (implementation), three (evaluation) and four (disposition).

\section{Method}

\subsection{Approach and context}

This research prioritizes a qualitative case study methodology that focuses on a limited number of cases that are considered significant given the specific objective of the study (Merriam, 1988). This type of methodology allows researchers to investigate thoroughly a phenomenon, or a group of individuals in order to have an accurate and complete description and interpretation (Merriam, 1988). In this study, the case is an entrepreneurial school where teachers have prioritized pedagogical projects to implement interdisciplinarity. The school is located in a disadvantaged area, with a deprivation index of 10/10 (Note 5), and welcomes students from elementary (kindergarten to grade six) and secondary (secondary one to three) levels for a total of close to 200 pupils. The school has integrated an entrepreneurial 
component into its success plan and used educational projects, in which many interdisciplinary projects are deployed. These educational orientations are based on socio-economic context in order to foster students' intrinsic motivation, self-knowledge and sense of belonging.

\subsection{Tool and participants}

An individual interview was favored to be able to meet the specific objective of this study. This type of interview gathers the opinions and views of participants to facilitate understanding and interpretation of realities (Poupart, Deslauriers, Groulx, Laperrière, Mayer, $\&$ Pires, 1997). The individual interview allows deep understanding of the phenomenon studied since it focuses and gives direct access to the lived experience of the participants (Savoie-Zajc, 2009; Yin, 2014). The individual interviews included 20 questions aligned with Proulx's four steps (2004) and the duration of these interviews varied between 25 minutes and 61 minutes. We conducted eight individual interviews with the school staff. Table 1 illustrates the characteristics of the participants.

Table 1. Characteristics of participants in individual interviews

\begin{tabular}{lll}
\hline Teaching levels & Discipline/Duties & $\begin{array}{l}\text { Teaching experience } \\
\text { in the school }\end{array}$ \\
\hline \multirow{3}{*}{ Elementary teaching } & Kindergarten $(\mathrm{n}=1)$ & 23 years \\
\cline { 2 - 3 } & Cycle 1 $(\mathrm{n}=1)$ & 10 years \\
\cline { 2 - 3 } & Cycle 2 $(\mathrm{n}=1)$ & 1 year \\
\cline { 2 - 3 } & Cycle 3 $(\mathrm{n}=1)$ & Few months \\
\cline { 2 - 3 } & School principal $(\mathrm{n}=1)$ & 2 years \\
\hline Secondary teaching & Mathematics tutor $(\mathrm{n}=1)$ & 9 years \\
\cline { 2 - 3 } & School principal $(\mathrm{n}=1)$ & 2 years \\
\hline $\begin{array}{l}\text { Elementary and } \\
\text { secondary }\end{array}$ & $\begin{array}{l}\text { Fine arts and drama, } \\
(\mathrm{n}=1)\end{array}$ & 10 years \\
\hline
\end{tabular}

\subsection{Data analysis}

The completed interviews were transcribed and the qualitative data were analyzed using Boutin's strategy (2007). This method is divided into four stages: 1) preliminary readings of the data and establishment of the list of statements; 2) grouping statements into predetermined categories (theoretical framework); 3) identification of sub-categories; and 4) interpretation and description of results. This analysis procedure uses predetermined categories in the literature. For this study, the four stages of Proulx (2004) are the starting categories. The NVivo 10 software was used as a support to conduct these analyzes. A validation process with two judges was achieved and the percentage obtained was $95 \%$ for the entire corpus analyzed, recommended by Yardley (2008).

\section{Findings}


The results are presented according to Proulx's (2004) four steps. The teachers' main points of view as well as those of the school principals will be examined.

\subsection{Preparation (step 1)}

This first step involves several elements concerning the preparation of interdisciplinary projects. As for the educational intention of the projects, the teachers interviewed indicated that the interdisciplinary projects must meet the objectives of the Quebec Education Program (QEP) and the competencies related to the school disciplines involved in the projects. A teacher makes this observation about the reality of secondary level: "When you develop an interdisciplinary project, everyone must have a account because you have a curriculum. We also have a program to follow, so we really have to respect this program ... From there, we will really have all the elements to touch in the subjects (T1(Note 6))". Another teacher addresses this aspect of educational intention: "The work that we do, the tools I have given myself are linked to the learning processes and the skills that I want to achieve. So my first goal is not to carry out an entrepreneurial project, but it is like an accessory" (T5). Concerning the choice of the theme of the interdisciplinary projects, the teachers reports that this choice must first start with the ideas of the pupils and then, guide them in order to be able to make the connection within the goals of QEP and the academic disciplines. The duration of interdisciplinary projects varies greatly from one teacher to another. The project can last a few lessons or the entire school year by working on it every week, every month. School principals report that they have several roles to play in the preparation of interdisciplinary projects in this entrepreneurial context. They mainly facilitate the administrative and pedagogical organizations, plan formal and informal meetings around the preparation of projects with teachers, and offer support and resources to teachers to ensure the start of projects. In this area: "I work more in the order of the administrative organization at the schedules and after that is a little more in the pedagogical organization concerning the references to evaluate the pupils, for example" (SP1(Note 7)).

\subsection{Implementation (step 2)}

Several aspects should be considered regarding the implementation of interdisciplinary projects with pupils to ensure a common thread through the project. These aspects relate to motivation, leadership, collaboration between teachers and the work done by the pupils. Firstly, according to the teachers interviewed, it is essential to be motivated to conduct the interdisciplinary project in the entrepreneurial context. Thus, the motivation of the pupils to realize the project is reflected among teachers even though for some of them, the realization of any project can become a burden: "It also takes a project that turns on the teacher to motivate her pupils [...] I do not mean that it is the teacher only who decides, but something that turns us on and then we can stimulate pupils" (T3). For this reason, the school principal has an important role to play in supporting this motivation among teachers. Secondly, regarding leadership in implementing the projects, teachers report that they are responsible for leadership and that they are guides to support students in their various tasks for the duration of the project: "It is to provide a framework. I don't have to finish the letter, I don't have to finish creating the products, and I don't have to organize everything. It is up to them to 
decide [...] I am rather a guide for them" (T6). In the third place, there is no real consensus regarding the collaboration between teachers throughout the implementation of interdisciplinary projects due to the reality of elementary and secondary levels. To this end, there are more periods of collaboration at the secondary level and more openness on the part of teachers. The school schedule established with periods dedicated to the realization of the interdisciplinary projects facilitates this collaboration enormously. At the elementary level, there were few opportunities for collaboration. Teachers were left to themselves to conduct the interdisciplinary project with the pupils. They requested some help only occasionally. Below are two extracts of these realities: "We are in a small school and the collaboration is very good [...] when they are integral parts of the project [the teachers], it goes very well" (T1) and "It is not strong [the collaboration], there is none. We are all caught up in our project [...] but when you are in a project, to go to help the other in his project, it is difficult" (T5). Finally, asked about the students' work during interdisciplinary projects in entrepreneurial context, teachers emphasized that both teamwork (in the form of committees) and individual work were exploited to foster disciplinary competences, knowledge and cooperation. Here is an extract, from the individual interviews, which addresses this observation: "I do [the project] in small teams of 3 or 4 students usually. Sometimes, as that year, there was a single part because they had to compose sentences and I at the same time I can evaluate where they are at the level of their skills to write" (T4). More specifically in relation to teamwork, it appears that the older students (cycles two and three of elementary level and secondary level) have several roles to play in the various committees put in place within the interdisciplinary project. Most of the time, a leader was present in each committee: "We will usually find a finance team, a production team, a human resources team. We try as much as possible to respect this structure to distribute the role of each one within these structures. Inside the committee, there is a person in charge of each committee to have accountability" (T1). For young students (kindergarten, cycle one of elementary level), they often perform the same task at the same time before carrying out a second task of the project. Finally, school principals indicated that they must be able to provide human and financial resources and some time off to ensure effective follow up with each teacher and be able to resolve problems during the interdisciplinary project. These various roles facilitate the implementation of interdisciplinary projects by the teachers. To this end: "Our role is to equip them [the teachers], to ensure that the contacts they need with the community are made. Often when there is a problem, we are there to solve them. It is also to allow them to have time to be able to readjust their projects" (SP2).

\subsection{Evaluation (step 3)}

Following the analysis of the results, it appears that for most of the teachers interviewed, interdisciplinary projects have a learning support and recognition of competencies functions. Teaching must be based on the QEP to integrate competencies, related to school disciplines, and the teachers also assessed cross-curricular competencies through these projects. A teacher brings this evaluation example: In the competencies [from QEP], there is "Openness to the world", I can use this skill. There is "Fine motor skills", I can use them too, "Cooperation": is he able to work with others, to encourage his friend. There are several things I can use for my assessment. In kindergarten, I use more observation, so I can take fewnotes" (T2). It should be 
noted that since interdisciplinary projects are deployed in the context of entrepreneurship, entrepreneurial skills are also evaluated by teachers, such as teamwork, leadership and a sense of responsibility. Several assessment tools were used by teachers. The main ones were the self-assessment, the daily logbook and the observation checklist. These tools can be used for both the assessment of entrepreneurial skills and the evaluation of disciplinary competences targeted in the projects and these evaluations are done throughout the project. In this step, participants were asked about the potential effects of these interdisciplinary projects on students and teachers. It is interesting to note that, according to the teachers interviewed, interdisciplinary projects in the entrepreneurial context increased motivation, and a sens of ownership and pride among students. Moreover, they fostered the reinvestment of knowledge and gave meaning to the learning experience. Finally, these projects were perceived to have the potentiel to improve teamwork and cooperation among pupils. One teacher commented on this aspect: "The project develop their motivation, involvement, autonomy, responsibility and I think they take consciousness [the students] that there are learning they need" (T6). Teachers emphasized that these projects enabled them to discover new qualities and create new relationships with students: "It also allows to see and recognize the qualities of students other than in an ordinary course that I do not necessarily see [...] It allows [me] to discover certain qualities among my pupils" (T5). In addition, these projects increased self-motivation and self-satisfaction as teachers and allowed the integration of new non-traditional teaching practices. One teacher stated: "Yes it can be difficult to manage [interdisciplinary projects in an entrepreneurial context] because we are more in a traditional classroom but it is another learning process that can be very interesting" (T1). School principals noted that these interdisciplinary projects deployed in the entrepreneurial school allowed them to create new links with students and increased their sense of pride and satisfaction. On the other hand, implementation of these projects increased their level of stress and required rigor and structured planning. A member of the school principal group raised this observation: "For me, that leads me to have a better rigor. That is another vision. Since it is in the educational project, there are expectations. So I have to see that expectations are met" (SP1). An interesting observation emerged from the school principals concerning the evaluation of the interdisciplinary projects deployed in an entrepreneurial context. They noted the importance of setting up clear evaluation mechanisms for the assessment of interdisciplinary projects because presently, there is no formal planning in this sense. As a result, each teacher decided whether to evaluate the interdisciplinary project in order to make a judgment on the development of the competencies or whether these projects have a learning support evaluation function. In this regard: "We have not been able to plan the evaluation aspect in terms of notes on the school report, but we may be able to evaluate more qualitatively [...] There has been no objectives clearly articulated around interdisciplinary. There are no mechanisms in place [for evaluation]."(SP1).

\subsection{Disposition (step 4)}

Participants discussed several devices of disposition that were put in place when the interdisciplinary project ended. First, they can present the final outcome of the project to community members and parents who were project partners. In addition, every year there is 
an open house day where parents, families and members of the community are invited to visit the various interdisciplinary projects implemented during the school year. These projects are also discussed during meetings of the school council: "First, the school council, which is made up of parents, is informed of the progress of the projects to all the councils. It is a mode of diffusion. There are also parents who are aware because they are solicited by their child. If it is the realization of an event, the parents are invited [...] we do an open house day in May to the community" (SP2). Through a discussion process with the pupils, the teachers assessed the interdisciplinary projects by providing feedback on the objectives and the learning acquired throughout the project. They want to know everything that students had learned from the project and be aware of the final result. School principals, on the other hand, ensured that teachers were ready to carry out the open house day by offering them various material resources or time savings and they ensured that they were present at these invitations where parents and members of the community were invited. Finally, we asked participants about the desirable improvements in the implementation and deployment of interdisciplinary projects in an entrepreneurial context. There was no real consensus among the participants to this effect, but a few observations caught our attention. It would be profitable to improve the interdisciplinary project in the entrepreneurial school and to have a continuation between the elementary and secondary levels and thus reinforce this project-based pedagogical culture: "Formalize the interdisciplinary aspect in which one implements a mechanism that will ensure that in the year, we have planning on projects that are recurring. Teachers need to be more sensitive of what students are learning. When they are sensitive, they will be able to make students sensitive" (SP1). Some teachers also indicated that it would be interesting to collaborate more with other teachers to facilitate the implementation of the interdisciplinary project and even to realize a school project where all the teachers would work together in the deployment of the project. A teacher said: "I would like that the projects are to be more interlinked. We're talking about an entrepreneurial school, could we have a school project where everyone gets involved, and then everyone is proud to participate and that makes the whole school move forward?" (T6). In our sample, there were two teachers who had recently been employed at this school (replacement contract of a few months and a year) and they would have liked to have more information, resources and support to realize the interdisciplinary projects in this entrepreneurial school context. Here are two excerpts that support this observation: "More time to be released with a student committee, to set the stages, to set a timetable. We move forward and try to close things up as we go along. Long-term perception is not possible" (T3) and "Then, as I arrive [in the school], I would need someone to talk to me about the school's vision entrepreneurship and the interdisciplinary project to be achieved” (T6).

\section{Discussion}

\subsection{Preparation (step 1)}

At this step related to project preparation, the reality of teaching by disciplines at the secondary level added an additional constraint to plan and integrate different school subjects in the interdisciplinary project. It seems important to have consensus and collaboration so that each teacher can reach the objectives of the QEP and develop the skills related to a discipline. 
This is in line with the Hasni and his colleagues (2015) and LeDoux's (2003) findings in that the integration of interdisciplinary projects into secondary level brings additional challenges for school staff to meet the requirements of each discipline according to the QEP. Teachers also mentioned that the main goal of interdisciplinary projects in this entrepreneurial context was to develop the disciplinary skills and learning of students. The entrepreneurial context serves as a pretext to realize the interdisciplinary project. This result is consistent with the literature (European Commission, EACEA, \& Eurydice, 2012; Pepin, 2011) that argues entrepreneurship is a privileged context to support the implementation of interdisciplinary and get students to acquire new knowledge. A final observation draws our attention at this step. At the beginning of the project, it's necessary to take into consideration the students' ideas for the choice of the theme to be exploited in the project, but at the same time, the teachers must guide them in order to make the connection with the QEP. Arpin and Capra (2001) and LeDoux (2003) have rightly emphasized the key role of the teacher as a pedagogical mediator and guide between the student and the learning to be acquired in the project. In summary, this step of preparation emphasizes the importance of planning the interdisciplinary project in order to meet the requirements of the QEP and to leave certain latitude to the students.

\subsection{Implementation (step 2)}

In the light of the results, the teacher assumes a large majority of the leadership involved in the implementation of the project, but students must be able to take on the various tasks related to the interdisciplinary project. This result echoes the literature (Perrenoud, 1998; Proulx, 2004), emphasizing that the project must be fully completed by the pupils, from preparation to disposition. This is one of the objectives and features of project pedagogy, and teachers seem to leave this place to the pupils in order to optimize their learning. A second interesting result emerged from our study. According to the participants' comments, there was an interesting collaboration among secondary school teachers, which greatly facilitated the integration of interdisciplinary approaches into the projects deployed in the entrepreneurial context. In return, there was little real collaboration among elementary school teachers in implementing interdisciplinary projects, despite the fact that they have mentioned that it would be desirable to have more opportunities to collaborate in order to conduct the interdisciplinary project in the entrepreneurial context. In our view, it is necessary to increase collaboration between school staff. In this line of thought, Hammond and McCallum (2009) note that a high level of collaborative work among school staff members is important in order to promote the integration of interdisciplinarity into projects. Hasni (2010) reiterates and highlights that one of the important conditions for the implementation of interdisciplinarity is precisely the commitment and availability of teachers to work together. In order to have more opportunities for collaboration, it would be interesting to schedule formal meetings among the teachers to discuss the progress of the projects and the encountered difficulties in order to find team solutions. Teachers could form experienced/novice pairs to take advantage of the expertise of experienced teachers to assist new teachers in realization of the interdisciplinary projects. These hypotheses could be investigated in future research. Another observation emerged in this step in relation to tasks realized by students during the deployment of 
interdisciplinary projects. According to the staff interviewed, older students work more in teams in small committees, while younger students realize more tasks together in large groups. Klein (1998) finds that these two working methods are used to foster the integration and development of a sense of belonging in learning during an interdisciplinary project.

\subsection{Evaluation (step 3)}

A first observation is that interdisciplinary projects combine two functions of the evaluation, namely the learning support function (formative evaluation) and the recognition of competencies (summative evaluation) (Fourez, Maingain, \& Dufour, 2002; Ministère de l'Éducation du Québec, 2002). Interestingly, teachers are trying to take advantage of the full potential of these interdisciplinary projects in order to reinvest what the students learned and to evaluate in order to make a judgment about the skills they developed. With this in mind, school staff tried as much as possible to match the assessment of school disciplines and entrepreneurial skills in order to achieve both, the goals of the QEP and the objectives of entrepreneurship. Thus, the implementation of the interdisciplinary project in an entrepreneurial context can become more meaningful for the pupils and maximize the teaching time, but rigorous planning is essential in order to evaluate these interdisciplinary projects. When asked about the potential effects of interdisciplinary projects on students and teachers, the findings in this study were consistent with those found in the literature (Bell, 2010, Hasni et al., 2008) and highlight the positive implications of increasing motivation and give meaning to the learning experience. Despite the fact that most teachers set up evaluation mechanisms during the deployment of interdisciplinary projects, it seems that this aspect would still have to be improved in order to have a formal planning of the interdisciplinary projects and the evaluation of the disciplines involved in all projects deployed at the elementary and secondary levels. This formal planning could ensure the integration and evaluation of the disciplines involved in the projects and would enable a genuine measure of the students' acquisition of knowledge and skills. The implementation of interdisciplinary projects in the entrepreneurial context allows the introduction of new teaching practices and constitutes a non-traditional teaching method. This result supports the study by Samson and colleagues (2012) that interdisciplinary projects facilitate the integration of innovative and motivating teaching practices. Hasni (2010) addresses these conclusions and adds that interdisciplinarity is associated with risk teaching contrary to traditional and disciplinary teaching. This type of practice can create additional challenges for school staff, but as evidenced by our findings, the potential impact is positive for students, teachers and school principals.

\subsection{Disposition (step 4)}

This last step emphasizes the importance of having a formal presentation of the completed project in order to present it to families and community members. These actors are often asked to optimize the interdisciplinary project in an entrepreneurial context (Boulanger, Rivard, \& Deslandes, 2017; MELS, 2006). In this stage, which is linked to the disposition of the project, it is also essential for teachers to review the learning achieved throughout the interdisciplinary project and the academic and entrepreneurial skills developed. Students are 
able to thinking about the overall process surrounding project implementation and the potential impact of the project on them. This step is important and should not be neglected in order to optimize the benefits related to learning. A recommendation resulting from the individual interviews drew our attention in that it may be difficult for a teacher who starts in an entrepreneurial school to implement an interdisciplinary project in this specific context in addition to performing all the other tasks expected in education. This observation reiterates the importance of closer collaboration between teachers in order to facilitate the implementation of the project. New teachers would feel more supported and equipped to realize the project, since close collaboration between teachers reduces isolation (Pompson, 2005) and leads to shared teaching strategies (Erickson, 1996). An interesting parallel can be drawn between this observation and the professional integration of teachers, where the studies highlight the importance of supporting, collaborating and offering support to teachers in order to promote their professional development (Fantilli \& McDougall, 2009). In this perspective and as Hasni (2010) emphasizes, it would also be important to propose more resources (human, financial, time release) to support new teachers from preparation to the disposition of project. To this end, the institutional context is one of the key conditions for success in the implementation of interdisciplinary projects (Fourez et al., 2002).

\section{Conclusion}

The aim of this study was to describe the processes of implementation and deployment of interdisciplinary projects in the context of an entrepreneurial school. The theoretical framework of Proulx (2004) provided an overall picture of the steps involved to realize a project with the students. In light of the results and the discussion that followed, it seems that each of the steps brings its own challenges in line with the consolidation of interdisciplinary projects in an entrepreneurial context. In this regard, it is essential that the projects be conducted entirely by the students, but the teacher has a key role of guide students in order for them to complete the project and meet the objectives of the QEP. The principal goal of these projects is the development of skills and competencies related to the school disciplines involved. Moreover, it would be interesting to have closer collaboration between the teachers in order to implement the interdisciplinary projects. This collaboration has many advantages and enables new teachers to be better equipped to meet the academic and entrepreneurial objectives of the project. In this regard, it would be advantageous to offer more support to new teachers in order to reduce the workload associated with the project. In conclusion, despite the fact that interdisciplinary project teaching is a non-traditional method of teaching, it seems that the combination of interdisciplinary and entrepreneurship is working to encourage the development of disciplinary learning and entrepreneurial skills. It seems that teachers want to take advantage of the entrepreneurial context to implement interdisciplinary projects in order to benefit from the full potential and advantages of interdisciplinarity. In summary, it would be interesting for teachers wishing to integrate interdisciplinarity in pedagogical projects to consider school entrepreneurship as a context favorable for the realization of interdisciplinary projects.

\section{Acknowledgements}


The authors wish to express their thanks to the school staff who agreed to participate in this study.

\section{References}

Arpin, L., \& Capra, L. (2001). L’apprentissage par projets. Montréal, QC: Chenelière/McGraw-Hill.

Bell, S. (2010). Project-based learning for the $21^{\text {st }}$ Century: Skills for the future. The Clearing House, 83, 39-43. https://doi.org/10.1080/00098650903505415

Blumenfeld, P. C., Soloway, E., Marx, R.W., Krajcik, J. S., Guzdial, M., \& Palincsar, A. (1991). Motivating project-based learning: Sustaining the doing, supporting the learning. $\begin{array}{lll}\text { Educational } \quad \text { Psychologist, } & \text { 369-398. }\end{array}$ https://doi.org/10.1080/00461520.1991.9653139

Boulanger, M., Rivard, M.-C., \& Deslandes, R. (2017). L'intégration de l'interdisciplinarité dans les projets réalisés en contexte entrepreneurial: points de vue du personnel scolaire. Revue canadienne des jeunes chercheur(e)s en éducation, 8(1), 18-27. Retrieved from https://journalhosting.ucalgary.ca/index.php/cjnse/article/view/30778

Boutin, G. (2007). L'entretien de groupe en recherche et formation. Montréal, QC: Éditions nouvelles.

Cone, T. P., Werner P, Cone S. L., \& Woods A. M. (1998). Interdisciplinary teaching through physical education. Champaign, IL: Human Kinetics.

Erickson, L. (1996). Designing integrated curriculum that promotes higher level thinking. Alexandria, VA: Association for Supervision and Curriculum Development.

European Commission. (2013). Communication from the commission to the European parliament, the council, the European economic and social committee and the committee of the regions entrepreneurship 2020 action plan, Reigniting the entrepreneurial spirit in Europe. Brussels, Belgium: European Commission .

European Commission, EACEA, \& Eurydice. (2012). Developing key competences at school in Europe: Challenges and opportunities for policy. Eurydice Report. Luxembourg: Publications Office of the European Union. https://doi.org/10.2797/93204

Eurydice Network. (2012). Entrepreneurship education at school in Europe. National strategies, curricula and learning outcomes. Brussels, Belgium: Education, Audiovisual and Culture Executive Agency. https://doi.org/10.2797/80384

Fantilli, R., \& McDougall, D. E. (2009). A study of novice teachers: Challenges and supports in the first years. Teaching and Teacher Education, 25(6), 825-841. https://doi.org/10.1016/j.tate.2009.02.021

Fourez, G., Maingain, A., \& Dufour, B. (2002). Approches didactiques de l’interdisciplinarité. Bruxelles, Belgique: De Boeck 
Grant, M. M. (2002). Getting a grip on project-based learning: Theory, cases and recommendations. Meridian: A Middle School Computer Technologies Journal, 5(1), 1-17. Retrieved from https://projects.ncsu.edu/meridian/win2002/514/

Hammond, C., \& McCallum, F. (2009). «Interdisciplinarity: bridging the University and field of practice divide». Australian Journal of Teacher Education, 34(2), 50-63. https://doi.org/10.14221/ajte.2009v34n2.5

Hasni, A. (2010). L'éducation à l'environnement et l'interdisciplinarité: de la contextualisation des savoirs à la scolarisation du contexte? Dans A. Hasni \& J. Lebaume (Ed.), Enjeux contemporains de l'éducation scientifique et technologique (pp. 179-222). Ottawa, Ontario: Les Presses de l'Université d'Ottawa.

Hasni, A., Lenoir, Y., \& Froelich, A. (2015). Mandated interdisciplinarity in secondary school: The case of science,technology, and mathematics teachers in Quebec. Issues In Interdisciplinary Studies, 33, 144-180. Retrieved from https://oakland.edu/Assets/Oakland/ais/files-and-documents/Issues-in-Interdisciplinary-Studi es/volume-33/AISissues15pdf5hasnietal.pdf

Hasni, A., Lenoir, Y., Larose, F., Samson, G., Bousadra, F., \& Dos Santos, C. (2008). Enseignement des sciences et technologies et interdisciplinarité: point de vue d'enseignants $\mathrm{du}$ secondaire au Québec. Dans A. Hasni \& J. Lebeaume (Ed.), Interdisciplinarité et enseignement scientifique et technologique (pp.75-110). Sherbrooke-Lyon : Éditions du CRP-INRP.

Huber, L. R., Sloof, R., \& Van Praag, M. (2014). The effect of early entrepreneurship education: Evidence from a field experiment. European Economic Review, 72, 76-97. https://doi.org/10.1016/j.euroecorev.2014.09.002

Klein, J. T. (1998). L'éducation primaire, secondaire et postsecondaire aux États-Unis: vers l'unification du discours sur l'interdisciplinarité. Revue des sciences de l'éducation, XXIV(1), 51-74. https://doi.org/10.7202/031961 ar

Larose, F., \& Lenoir, Y. (1998). «La formation continue d'enseignants du primaire à des pratiques interdisciplinaires: résultats de recherches». Revue des sciences de l'éducation, 24(1), 189-228. https://doi.org/10.7202/031967ar

Ledoux, A.M. (2003). Le travail en projet à votre portée. Anjou, QC: Édition CEC.

Lenoir, Y. (2013). Interdisciplinarity in francophone education: The weal and woe of research journey. Issues in Interdisciplinary Studies, 31, 123-148. Retrieved from https://our.oakland.edu/handle/10323/4483

Mansilla, B. V. (2005). Assessing student work at disciplinary crossroads. Change: The Magazine of Higher Learning, 37(1), 14-21. https://doi.org/10.3200/CHNG.37.1.14-21

Ministère de l'Éducation du Québec. (2002). L'évaluation des apprentissages au préscolaire et au primaire. Cadre de référence. Québec, QC: Gouvernement du Québec. 
Ministère de l'éducation du Québec. (2003). Bulletin statistique de l'éducation. La carte de la population scolaire et les indices de défavorisation. Québec, QC: Gouvernement du Québec.

Ministère de l'Éducation, du Loisir et du Sport. (2005). Invitation à la culture entrepreneuriale: guide d'élaboration de projet à l'intention du personnel enseignant. Québec, QC: Gouvernement du Québec.

Ministère de l'Éducation, du Loisir et du Sport. (2006). Développer et vivre une culture entrepreneuriale au primaire et au secondaire. Québec, QC: Gouvernement du Québec.

Merriam, S. B. (1988). Case study research in education: A qualitative approach. San Francisco: Jossey-Bass.

Pépin, M. (2011). L'entrepreneuriat en milieu scolaire: de quoi s'agit-il? McGill Journal of Education, 46(2), 303-326. https://doi.org/10.7202/1006441ar

Perrenoud, P. (1998). Réussir ou comprendre? Les dimensions classiques d'une démarche de projet. Genève, Suisse: Université de Genève.

Pompson, A. (2005). One classroom at a time? Teacher isolation and community viewed through the prism of the particular. Teacher College Record, 107(4), 783-802. Retrieved from https://eric.ed.gov/?id=EJ687740

Poupart, J., Deslauriers, J.-P., Groulx, L.-H., Laperrière, A., Mayer, R., \& Pires, A. P. (1997). La recherche qualitative. Enjeux épistémologiques et méthodologiques. Boucherville, QC: Gaëtan Morin Éditeur.

Proulx, J. (2004). L'apprentissage par projet. Québec, QC: Presses de l’Université du Québec (PUQ).

Samson, G., Hasni, A., \& Ducharme-Rivard, A. (2012). «Constats et défis à relever en matière d'intégration et d'interdisciplinarité: résultats partiels d'une recension d'écrits». Revue des sciences de l'éducation de McGill, 47(2), 193-212. https://doi.org/10.7202/1013123a

Savoie-Zajc, L. (2009). L'entrevue semi-dirigée. Dans B. Gauthier (Ed.), Recherche sociale: de la problématique à la collecte des données (5éd., pp. 337-360). Québec, QC: Presses de l’Université du Québec (PUQ).

Schneider, S. (1997). Defining and teaching environmental literacy. Trends in Ecology and Evolution, 12(11), 457. https://doi.org/10.1016/S0169-5347(97)01207-X

Secrétariat à la jeunesse. (2004). Défi de l'entrepreneuriat jeunesse, plan d'action triennal 2004-2005-2006. Québec, QC: Gouvernement du Québec.

Secrétariat à la jeunesse. (2016). Stratégie d'action jeunesse 2016-2020. Québec, QC: Gouvernement du Québec.

Thomas, J. W. (2000). A review of research on project-based learning. San Rafael, CA: The Autodesk Foundation. 


\section{Macrothink}

Yardley, L. (2008). Demonstrating validity in qualitative research. In J. A. Smith (Ed.), Qualitative psychology: A practical guide to research methods (pp. 235-251). London, United Kingdom: Sage.

Yin, R. K. (2014). Case study research: Design and methods ( $5^{\text {th }}$ ed.). Thousand Oaks, CA: Sage Publications.

\section{Copyright Disclaimer}

Copyright reserved by the author(s).

This article is an open-access article distributed under the terms and conditions of the Creative Commons Attribution license (http://creativecommons.org/licenses/by/3.0/).

\section{Endnotes}

Note 1. https://www.nfte.com/what/mission

Note 2. http://www.theeia.com/article/4/about-us/31/our-vision.html

Note 3. http://jacanada.org/who-we-are

Note 4.

http://www.thelearningpartnership.ca/what-we-do/student-programs/entrepreneurial-adventur e

Note 5. In Quebec, the socio-economic environment index (EEI) is calculated by the Ministry of Education of Quebec (2003). The index takes into account the mother's schooling (weighted at $66 \%$ ) and the proportion of parents who were not employed the previous year (weighted at $33 \%$ ), without considering the family's income. This information, obtained from Statistics Canada, was compiled for the 2001 census from a sample number of households (families).

Note 6. T1: Teacher 1

Note 7. SP1 : School principal 1 